\title{
Business Uncertainty As A Factor of A Corporate Strategy
}

\author{
Victor S. Efremov \\ Professor, Faculty of Economics \\ RUDN University \\ Moscow, Russia \\ efremov_vs@pfur.ru
}

\author{
Irina G. Vladimirova \\ Professor, Faculty of Economics \\ RUDN University \\ Moscow, Russia \\ vladimirova_ig@pfur.ru
}

\begin{abstract}
The company's development strategy in modern economic and managerial science is viewed primarily as a phenomenon associated with intra-firm dynamics. All attention is focused on how the organizational and economic structure of the company is changing and what economic effect this leads to. The obvious fact, however, is that changing the way a firm "enters" into its business space as a result of implementing a chosen development strategy simultaneously with intra-firm changes leads to shifts in the system of relations in its external environment, changing the conditions for the formation of the final value and the structure of the value chain as a whole. We believe that not the least role in determining the development strategy of the company is played by its desire to make achieving the target business result more definite. In this article, we would like to show how one can assess the change in the degree of uncertainty in the process of projecting corporate strategy.
\end{abstract}

Keyword-uncertainty, entropy, integration, business concentration, corporate strategy

\section{INTRODUCTION}

The choice of the firm's strategy, whether it is aimed at its development or overcoming the consequences of the crisis, can hardly be caused solely by the desire for maximum economic efficiency of its production and commercial activities. Horizontal or vertical integration, conglomerate or concentric diversification of production, development of markets or product line lead to an increase in the internal complexity of the firm as an object of management, and this is a direct way to increase the transformation costs, without much hope of simplifying the work of coordinating the firm's operations in the market and saving on transactional costs, respectively [1]. What can force the firm's governance to make a deliberate complication of the management object and a corresponding increase in costs?

The object of management, in contrast to the subject of contractual relations, is fully controlled by the management of the firm. The desire to put the subject of contractual relations under full control can be explained by the intention or necessity of obtaining a higher degree of certainty of achieving a certain production and commercial result. But is it always possible with the expansion of the boundaries of the integration of a firm into the business space that can be obtained?

Studying the laws of tectology, Alexander Bogdanov [2] has formulated a very important conclusion regarding the mutual influence and interdependence of the characteristics of the organization and the environment in which it is located. First of all, it concerns the cause of the emergence and development of organizational entity in some environment - the desire for quantitative and structural stability. With other equal characteristics of the homogeneity of the environment, small organizational formations are smaller in comparison with large quantitative stability and tend to disappear (degradation). On the other hand, large organizational formations have less structural stability and gravitate towards collapse (disintegration). To measure the degree of uncertainty of the production-commercial result, one can use the entropy index of business space, calculated as follows:

$$
H(X)=\sum_{i=1}^{n} p_{i} \cdot \log _{n}\left(\frac{1}{p_{i}}\right)=-\sum_{i=1}^{n} p_{i} \cdot \log _{n}\left(p_{i}\right)
$$

where: $\mathrm{p}_{\mathrm{i}}-\mathrm{a}$ share of the $i^{\text {th }}$ production-commercial process's results on the market; $\sum_{i=1}^{n} p_{i}=1$.

The evaluation of the share of production-commercial processes' results on the market varies depending on how many links in the value chain are taken into consideration. For example, taking into account only one direct production link in the value chain of the cement production system, outside its links with subsequent processing or transportation to the consumer, the entropy of the business is calculated by market shares covered by different cement companies (Table 1):

TABLE I. CEMENT COMPANIES’ MARKET SHARES (EXAMPLE).

\begin{tabular}{|c|c|c|}
\hline Company & Sales (ths. tones) & Market share \\
\hline Eurocement & $\mathbf{5 6 9 4 . 6}$ & $\mathbf{0 . 4 5 9}$ \\
\hline Holcim & $\mathbf{1 2 7 8 . 5}$ & $\mathbf{0 . 1 0 3}$ \\
\hline Lafarge & $\mathbf{1 4 8 6 . 2}$ & $\mathbf{0 . 1 2}$ \\
\hline Inteco & $\mathbf{2 2 2 8 . 6}$ & $\mathbf{0 . 1 7 9}$ \\
\hline Mordovcement & $\mathbf{8 0 4}$ & $\mathbf{0 . 0 6 5}$ \\
\hline Other & $\mathbf{9 2 6 . 8}$ & $\mathbf{0 . 0 7 5}$ \\
\hline Total: & $\mathbf{1 2 4 1 8 . 7}$ & 1 \\
\hline
\end{tabular}


Based on the data in Table 1, the entropy of the cement companies' business is calculated as follows (Table 2):

TABLE II. ENTROPY OF THE CEMENT COMPANIES’ BUSINESS (EXAMPLE).

\begin{tabular}{|c|c|c|c|}
\hline Company (i) & $p_{i}$ & $\log _{6}\left(p_{i}\right)$ & $p_{i} \bullet \log _{6}\left(p_{i}\right)$ \\
\hline Eurocement & $\mathbf{0 . 4 5 9}$ & $-\mathbf{0 . 4 3 5 2}$ & $-\mathbf{0 . 1 9 9 5}$ \\
\hline Holcim & $\mathbf{0 . 1 0 3}$ & -1.2689 & $-\mathbf{0 . 1 3 0 6}$ \\
\hline Lafarge & $\mathbf{0 . 1 2}$ & $-\mathbf{1 . 1 8 4 9}$ & $\mathbf{- 0 . 1 4 1 8}$ \\
\hline Inteco & $\mathbf{0 . 1 7 9}$ & $-\mathbf{0 . 9 5 8 7}$ & $-\mathbf{0 . 1 7 2 1}$ \\
\hline Mordovcement & $\mathbf{0 . 0 6 5}$ & $-\mathbf{1 . 5 2 8 7}$ & $-\mathbf{0 . 0 9 8 9}$ \\
\hline Other & $\mathbf{0 . 0 7 5}$ & $-\mathbf{1 . 4 4 8 4}$ & $-\mathbf{0 . 1 0 8 1}$ \\
\hline Total: & 1 & & $\mathbf{H}=\mathbf{0 . 8 5 1 0}$ \\
\hline
\end{tabular}

The value of the business entropy index is related to the inverse relationship with the concentration level of the commodity supply in the market. The lower the concentration of the commodity supply, the closer the model of competition in the industry to the perfect one, the higher the business entropy index. Conversely, the more the commodity supply is done by one seller, the closer the competition model to monopoly, the lower the business entropy index. With an increase in the level of monopolization of the industry, the value of the business entropy index in the limit tends to 0 . In the conditions of the perfect competition the business entropy index can reach a maximum value equal to 1 .

One of the most commonly used meters of industry concentration is the Herfindahl-Hirschman Index (HHI), calculated as the sum of squared shares of the commodity supply of all firms in the industry [3]. If the industry is completely monopolized, then $\mathrm{HHI}=1$. If the industry is in competition with a large number of small firms, then HHI tends to 0 . If only two firms operate in the industry, and they share the market equally, then $\mathrm{HHI}=0.5^{2}+0.5^{2}=0.5$. If there are 2 companies in the industry with market shares of 0.8 and 0.2 , then HHI $=0.8^{2}+0.2^{2}=0.68$, that is higher than in the case of two equal shares. In the latter case, it is obvious the industry is more monopolized than in the case with equal shares of the companies. A higher value of the index reflects this fact.

For our example above with cement companies, the value of the Herfindahl-Hirschman index is 0.28. This indicates a fairly low concentration of business and, therefore, high competition in the industry.

Table 2 shows that the market has a large concentration of the cement supply from Eurocement. If the share of Eurocement would be 0.309 (instead of 0.459), and the aggregate share of the companies classified in the group "Other" was 0.225 (instead of 0.075), the value of the business entropy index would be 0.9331 , which would characterize a higher level of competition in the industry. It is significant, that the Herfindahl-Hirschman index weakly reacts to structural changes in the business space. In this case, its value would decrease from 0.28 only to 0.20 . Entropy as a measure of the certainty of the production and commercial result, business concentration and competition is not only more sensitive to all structural changes, but also proves to be irreplaceable when it is necessary to take into account hierarchical links of companies in the business space. In fact, our hypothesis is that by taking a strategic decision regarding the depth of its vertical integration, the companies take into account the possible change in the degree of business uncertainty. Our analysis, which is presented below, allows us to conclude that this assumption is valid.

\section{ANALYSIS}

Assume that companies have a two-level market penetration system. This means that their final consumers are buyers of products with a deeper degree of processing. For cement companies, such products will be concrete, reinforced concrete products, dry cement mixtures and others. If for the cement companies the cement produced by them would be the only products they supply to the market, then their final consumers would be concrete plants, iron-concrete production factories, wholesale and retail stores of building materials. If the level of such consumers turns out to be a link in the value chain of the cement companies themselves, then their end users are buyers of concrete, reinforced concrete, etc. This means that cement companies are penetrating not on the cement market only, but on the markets of concrete, reinforced concrete, dry cement mixtures and others (Fig. 1).

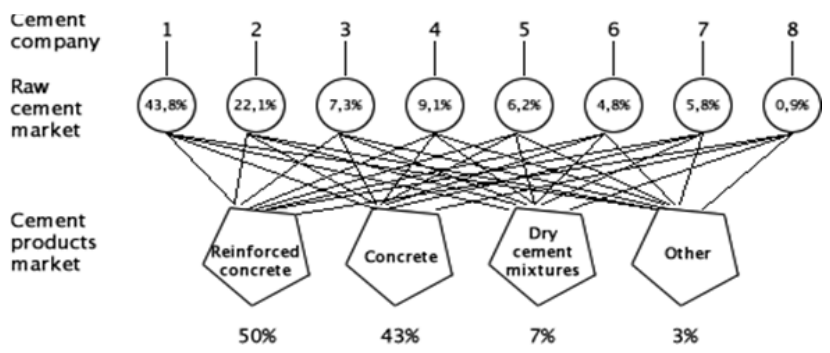

Fig. 1. Two-level market penetration scheme (example, where 1-Eurocement, 2-Inteco, 3-Lafarge, 4-Holcim, 5-Mordovcement, 6-Serebryakovcement, 7-SU 155,8 -Other).

At each level of this structure there will be a business entropy. Business entropy at the first level, calculated with (1), is equal to 0.784 :

$$
\begin{gathered}
H(X)=-\sum_{i=1}^{8} p_{i} \cdot \log _{8}\left(p_{i}\right)=-(0,438 \cdot \\
\log _{8}(0,438)+0,221 \cdot \log _{8}(0,221)+0,073 \cdot \\
\log _{8}(0,073)+0,091 \cdot \log _{8}(0,091)+0,062 \cdot \\
\log _{8}(0,062)+0,048 \cdot \log _{8}(0,048)+0,058 \cdot \\
\left.\log _{8}(0,058)+0,009 \cdot \log _{8}(0,009)\right)=0.784
\end{gathered}
$$

Business entropy at the second level, calculated with (1), is equal to 0.722 :

$$
\begin{gathered}
H(X)=-\sum_{i=1}^{4} p_{i} \cdot \log _{4}\left(p_{i}\right)=-\left(0,5 \cdot \log _{4}(0,5)+\right. \\
0,43 \cdot \log _{4}(0,43)+0,07 \cdot \log _{4}(0,07)+0,03 \cdot \\
\left.\log _{4}(0,03)\right)=0.722
\end{gathered}
$$

To determine the business entropy of cement companies in the markets for cement-based products (concrete, reinforced 
concrete products, etc.), it is necessary to calculate the proportion of the cement produced by each company in cement products of each type (Table 3 ). The sum of all shares in Table 3 is equal to 1 .

TABLE III. PROPORTION OF THE CEMENT PRODUCED BY EACH COMPANY IN CEMENT PRODUCTS OF EACH TYPE (EXAMPLE).

\begin{tabular}{|c|c|c|c|c|}
\hline \multirow{2}{*}{ Company (i) } & \multicolumn{4}{|c|}{ Share on the market of: } \\
\cline { 2 - 5 } & $\begin{array}{c}\text { Reinforced } \\
\text { concrete }\end{array}$ & Concrete & $\begin{array}{c}\text { Dry cement } \\
\text { mixtures }\end{array}$ & Other \\
\hline Eurocement & 0.219 & 0.1883 & 0.0307 & 0.0131 \\
\hline Inteco & 0.1105 & 0.095 & 0.0155 & 0.0066 \\
\hline Lafarge & 0.0365 & 0.0314 & 0.0051 & 0.0022 \\
\hline Holcim & 0.0455 & 0.0391 & 0.0064 & 0.0027 \\
\hline Mordovcement & 0.031 & 0.0267 & 0.0043 & 0.0019 \\
\hline Serebryakovcement & 0.024 & 0.0206 & 0.0034 & 0.0014 \\
\hline SU 155 & 0.029 & 0.0249 & 0.0041 & 0.0017 \\
\hline Other & 0.0045 & 0.0039 & 0.0006 & 0.0003 \\
\hline
\end{tabular}

This entropy, calculated with (1), is equal to 0.773 :

$$
H(X)=-\sum_{i=1}^{4} \sum_{j=1}^{8} p_{i j} \cdot \log _{32}\left(p_{i j}\right)=0.773
$$

where: $i$ - cement product's market index; $j-$ company's index.

Suppose that the company Holcim implements a strategy of direct vertical integration and acquires control over a number of concrete plants, providing $30 \%$ of all supplies of concrete to the market. Then the whole structure of the production-commercial result in the cement industry changes (Fig. 2).

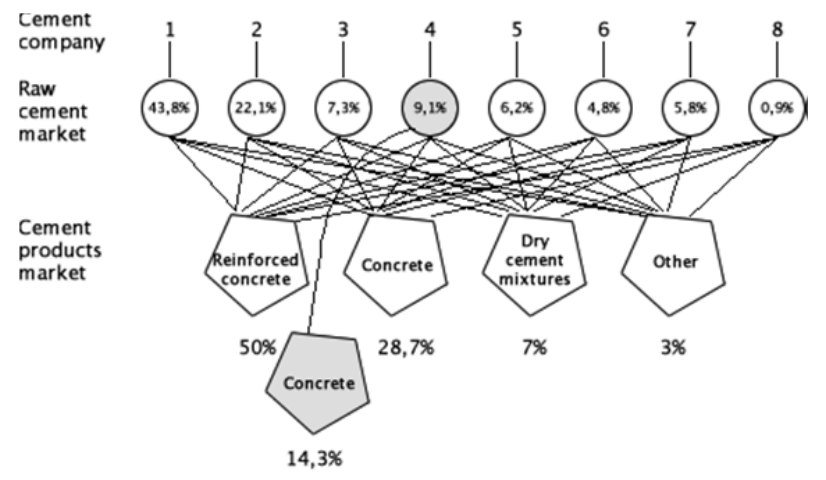

Fig. 2. Two-level market penetration scheme after Holcim direct vertical integration into the concrete market (example, where 1-Eurocement, 2-Inteco, 3-Lafarge, 4-Holcim, 5-Mordovcement, 6-Serebryakovcement, 7-SU 155, 8Other).
Alongside with this, the share of Holsim's cement changes in the total volume of concrete on the market, which entails a decrease in the cement business entropy as a whole to 0.696 .

Continuing the simulation, let's perform a partial vertical integration of Holsim's company into the market of reinforced concrete products. Suppose that the implementation of such a strategy can provide this company with a share of $8 \%$ of this market. At the same time, we assume that Eurocement takes control of $18.7 \%$ of the concrete market and $20 \%$ of the market for reinforced concrete products. Inteco takes control of $10 \%$ of the concrete market and $10 \%$ of the market for reinforced concrete products (Fig. 3).

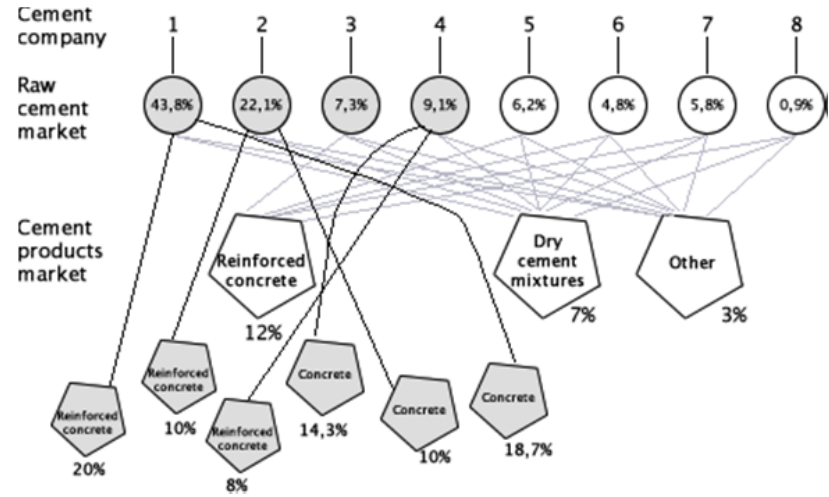

Fig. 3. Two-level market penetration scheme after Eurocement, Inteco and Holcim direct vertical integration into the concrete and reinforced concrete market (example, where 1-Eurocement, 2-Inteco, 3-Lafarge, 4-Holcim, 5Mordovcement, 6-Serebryakovcement, 7-SU 155, 8-Other).

Proportion of the cement produced by each company in cement products of each type after the vertical integration Holcim, Eurocement and Inteco are shown in Table 4.

TABLE IV. PROPORTION OF THE CEMENT PRODUCED BY EACH COMPANY IN CEMENT PRODUCTS OF EACH TYPE AFTER THE VERTICAL INTEGRATION HOLCIM, EUROCEMENT AND INTECO (EXAMPLE).

\begin{tabular}{|c|c|c|c|c|}
\hline \multirow{2}{*}{ Company (i) } & \multicolumn{4}{|c|}{ Share on the market of: } \\
\cline { 2 - 5 } & $\begin{array}{c}\text { Reinforced } \\
\text { concrete }\end{array}$ & Concrete & $\begin{array}{c}\text { Dry } \\
\text { cement } \\
\text { mixtures }\end{array}$ & Other \\
\hline Eurocement & $\mathbf{0 . 0 8 7 6}$ & $\mathbf{0 . 0 8 1 9}$ & $\mathbf{0 . 0 3 0 7}$ & $\mathbf{0 . 0 1 3 1}$ \\
\hline Inteco & $\mathbf{0 . 0 2 2 1}$ & $\mathbf{0 . 0 2 2 1}$ & $\mathbf{0 . 0 1 5 5}$ & $\mathbf{0 . 0 0 6 6}$ \\
\hline Lafarge & $\mathbf{0 . 0 0 8 8}$ & $\mathbf{0}$ & $\mathbf{0 . 0 0 5 1}$ & $\mathbf{0 . 0 0 2 2}$ \\
\hline Holcim & $\mathbf{0 . 0 0 7 3}$ & $\mathbf{0 . 0 1 3}$ & $\mathbf{0 . 0 0 6 4}$ & $\mathbf{0 . 0 0 2 7}$ \\
\hline Mordovcement & $\mathbf{0 . 0 0 7 4}$ & $\mathbf{0}$ & $\mathbf{0 . 0 0 4 3}$ & $\mathbf{0 . 0 0 1 9}$ \\
\hline Serebryakovcement & $\mathbf{0 . 0 0 5 8}$ & $\mathbf{0}$ & $\mathbf{0 . 0 0 3 4}$ & $\mathbf{0 . 0 0 1 4}$ \\
\hline SU 155 & $\mathbf{0 . 0 0 7}$ & $\mathbf{0}$ & $\mathbf{0 . 0 0 4 1}$ & $\mathbf{0 . 0 0 1 7}$ \\
\hline Other & $\mathbf{0 . 0 0 1 1}$ & $\mathbf{0}$ & $\mathbf{0 . 0 0 0 6}$ & $\mathbf{0 . 0 0 0 3}$ \\
\hline
\end{tabular}

Entropy of the cement companies business in this case becomes equal to 0.37 . 
Let's check the hypothesis about the influence of the industry's life cycle stage on the decision about the expediency of the vertical integration. To take into account the life cycle stage at which the industry is, we accept that there is a direct and stable correlation between the age of the industry and the level of unused production capacity. In the early stages (origin, development and growth) of the life cycle of the industry, all available production capacities are generally used in full. This is due, on the one hand, to the fact that production itself has not reached industrial scale (at the stage of origin and development). On the other hand, this may be due to the outstripping growth rates of demand compared to the supply.

At the stage of market saturation, under-capacity of production capacities begins to be observed. Over time, the level of unused capacity at this stage can reach $30-40 \%$. Further, as the market ages and deteriorates, the growth in the level of unused sectoral capacities continues until it becomes critical.

The entropy of business as a measure of the uncertainty of achieving an industrial and commercial result varies in the range $0 \leq H(X) \leq 1$. The maximum value of 1 is characteristic of a business for which there are no organizational or institutional instruments of certainty at all. Such a business is typical for the marginal model of an unorganized market with a perfect form of competition. The minimum value of entropy, equal to 0 , is typical for the business of a pure monopoly, on which the extremely clear and rigid organizational and legal framework of industrial and commercial activity is defined.

The quantity $1-H(X)$ is the reciprocal of entropy and characterizes the measure of the definiteness of the productioncommercial result.

Let's consider the following relation:

$$
D(X)=\frac{H(X)}{H_{\max }(X)-H(X)}=\frac{H(X)}{1-H(X)}
$$

It can be taken as a characteristic of the volatility of business conditions. It reveals the proportion between the uncertainty and certainty of production-commercial results. When the entropy approaches 1 , the variability of business conditions tends to infinity. The variability function $D(X)$ characterizes the extent to which the company is unable to control the conditions of its business.

On the contrary, the inverse of $\mathrm{D}(\mathrm{X})$ relation

$$
G(X)=\frac{H_{\max }(X)-H(X)}{H(X)}=\frac{1-H(X)}{H(X)}
$$

characterizes the degree of stability of business conditions. When the entropy of business approaches its maximum equal to 1 , this indicator tends to 0 . As the entropy decreases, this indicator tends to infinity.

Comparing $\mathrm{D}(\mathrm{X})$ and $\mathrm{G}(\mathrm{X})$, one can conclude that the business conditions can be more likely to be called stable than unstable if the business entropy $H(X) \leq 0,5$ :

$$
\begin{gathered}
D(X)=G(X) \Rightarrow \frac{H(X)}{1-H(X)}=\frac{1-H(X)}{H(X)} \Rightarrow \\
\Rightarrow H^{2}(X)-(1-H(X))^{2} \Rightarrow H(X)=\frac{1}{2}
\end{gathered}
$$

If $H(X)<0,5$, then $G(X)>D(X)$. And, conversely, when $H(X)>0,5$, then $G(X)<D(X)$.

On the other hand, the stability characteristic of business conditions can be defined by the following ratio:

$$
B(X)=\frac{H_{\max }(X)-H(X)}{H_{\max }(X)}=\frac{1-H(X)}{1}=1-H(X)
$$

It reveals the proportion of business entropy, eliminated by the actions of an organizational and legal nature, to the maximum possible entropy equal to 1 . When $H(X)=0$, the maximum value of the business stability indicator $B(X)$ is equal to 1 is reached. The stability function $\mathrm{B}(\mathrm{X})$ at the same time characterizes the degree of consistency of the company's business.

When $\mathrm{D}(\mathrm{X})$ and $\mathrm{B}(\mathrm{X})$ are compared, the margin of business volatility is determined at the level $\mathrm{H}(\mathrm{X})=0.382$ :

$$
D(X)=B(X) \Rightarrow \frac{H(X)}{1-H(X)}=\frac{1-H(X)}{1} \Rightarrow
$$

Thus, for entropy values $H(X)<0,382$ steady consistency of business conditions is observed, and for $H(X)>0,382$ entropy values their stable variability is observed.

Obviously, the degree of uncontrollability of the company's business environment is in unambiguous accordance with the entropy of the business. There can be both stable persistence, and unstable permanence or a persistent inconsistency in business conditions. The area of stable persistence of business conditions is the area corresponding to $0 \leq H(X)<0,382$. An area of unstable persistence of business conditions is the area corresponding to $0,382 \leq H(X)<0,5$. The region of stable volatility of business conditions is the region corresponding to $0,5 \leq H(X)<1$.

\section{CONCLUSION}

In the context of this study, the conclusion suggests that the company's strategic behavior with regard to vertical integration can be considered appropriate if it facilitates the transformation of its business space from the area of sustainable impermanence into a region of sustainable permanence.

\section{REFERENCES}

[1] Coase R.H. (1988), The Firm, The Market and The Law, The University of Chicago Press.

[2] Bogdanov A.A. (1989), Tektologiya: (Vseobshchaya organizatsionnaya nauka). v 2-kh kn., M.: Ekonomika.

[3] Hay, D.A. (1991) Industrial Economics and Organization: Theory and Evidence, 2nd edition, Oxford University Press. 